\title{
Factors affecting modal choice in urban mobility
}

\author{
Yannis Tyrinopoulos • Constantinos Antoniou
}

Received: 24 February 2012 / Accepted: 21 November 2012 /Published online: 18 December 2012

(C) The Author(s) 2012. This article is published with open access at SpringerLink.com

\begin{abstract}
Purpose This paper addresses the urban transit sector investigating variables affecting the habitual modal choices of commuters aiming to gain insight into the key factors affecting these choices and the reasons that discourage them from using public transport services.

Methods Probit and structural equation models have been estimated, while additional statistical analysis was performed to gain better insight of the commuters' mobility behavior. Results The analysis showed that the main factor affecting the preference of commuters toward passenger car is the availability of parking space. A preference of female respondents towards public transport was also evident, while, compared to the other age groups, respondents between the ages of 35 and 44 show a higher preference for car. Furthermore, crowding is the factor that most discourages respondents from the use of public transport. High fare, lack of public transport information and bad accessibility to the transit network do not seem to discourage respondents' use of public transport in the particular situation that was analyzed in this research.

Conclusions The paper demonstrated how the results drawn from the analysis can be used for tactical and strategic planning. For example, the fact that high fare levels do not discourage commuters from using public transport, may allow policy makers to slightly increase fares and redirect
\end{abstract}

\footnotetext{
Y. Tyrinopoulos $(\bowtie)$

Department of Civil Works and Infrastructure Technology, Faculty of Technological Applications, Technological Educational Institute of Athens, Aghiou Spyridonos,

12210 Egaleo, Greece

e-mail: yannist@teiath.gr

C. Antoniou

Laboratory of Transportation Engineering, National Technical

University of Athens (NTUA), 9 Heroon Polytechniou,

15780 Zografou, Athens, Greece

e-mail: antoniou@central.ntua.gr
}

additional revenue to improve other public transport services. Therefore, such findings may be quite useful for policy makers to better tackle commuters' perception and to define the appropriate urban mobility management actions and policies.

Keywords Urban mobility · Mode choice · Mobility behavior $\cdot$ Probit models $\cdot$ Structural equation models

\section{Introduction}

Sustainable mobility in urban areas is essential for the smooth operation of the local and national economy. Congestion, accidents, delays, air pollution and noise as well as infrastructure damage are some of the major adverse impacts associated with urban mobility. Urban traffic is responsible for $40 \%$ of $\mathrm{CO} 2$ emissions and $70 \%$ of emissions of other pollutants arising from road transport [16]. Furthermore, the number of road traffic accidents in towns and cities is also growing every year: one in three fatal accidents now happen in urban areas, and it is the most vulnerable people, namely pedestrians and cyclists, who are the main victims [16].

Increasingly over the recent years, particular attention has been paid to urban mobility by governmental bodies, policy makers, transport operators, researchers and user groups. It has been acknowledged that this issue requires collective effort and cooperative initiatives to be solved. The European Commission issued the Green Paper for urban mobility [16], which addresses the main challenges related to urban mobility through five core themes: Free-flowing towns and cities; Greener towns and cities; Smarter urban transport; Accessible urban transport; and Safe and secure urban transport. In addition, the Green Paper looks at means in order to help the creation of a new culture for urban mobility, including knowledge development and data collection, and 
addresses the issue of financing. With this Green Paper, the Commission wishes to launch a broad public debate as to what a European policy on this issue should contain.

The research community around the globe investigates urban mobility from various angles in an attempt to find new innovative tools, emerging ideas and approaches. They also aim to gain insight on the key aspects and elements that affect mobility and transit in urban areas. The eventual goal of all these efforts is to facilitate commuters' mobility and public transport, decongest road networks, reduce accidents and finally create a sustainable and environmentally friendly urban transport system. More practical solutions developed to address this issue, which are already operational in different forms and cities are infomobility services, advanced public transport systems and mobility centers. A mobility center is, in general, a service or facility that facilitates the mobility of citizens and travelers, and guides their modal choices in an urban environment.

This paper sheds light on the key factors and attributes that have particular impact on the choice of the available means of transport in urban areas and could encourage citizens in using public transport. More specifically, the paper addresses the urban transit sector investigating the key factors that affect the modal choice of commuters in their urban mobility and transit. Probit Models [47] have been estimated to determine the coefficients affecting modal choice, while a structural equation model has been estimated to better model the impact of the underlying mobility behavior of the travelers, using their responses as indicators. The research goes one step forward placing particular emphasis on public transport and analyzing the main reasons that discourage commuters from using local public transport services. The statistical analysis conducted in this research reveals useful information about the mobility behavior of commuters of different market segments. The data used were collected in a research project in Greece during the development of a mobility centre. The paper also presents a state-of-the-art review of major research and technological development initiatives, and scientific results on urban mobility.

\section{Literature and state-of-the-art review}

The research and academic communities as well as the various research and development projects have examined urban mobility from various standpoints. A brief overview of the most relevant and notable efforts is presented next classified in thematic topics.

\subsection{The role of spatial planning and land use}

In their research, Meurs and Haaijers [34] contributed to the clearer understanding of the extent to which the spatial structure and planning of the residential environment can explain mobility, in general, and the choice of transport mode, in particular, and what planning and traffic management aspects play a significant role in this. Their research demonstrated that mobility and the choice of transport modes are directly linked with the characteristics of the spatial environment. According to their conclusions, the "impact of the characteristics arising from the residential environment is considerable at $20 \%$, although this relative effect differs by mode of transport, from about $10 \%$ for car trips to $40 \%$ for journeys on foot" [34].

In a similar direction, Schwanen and Mokhtarian [42] studied the degree to which commute mode choice differs by residential neighborhood and by neighborhood type dissonance. The authors found that "neighborhood type dissonance is statistically significantly associated with commute mode choice: dissonant urban residents are more likely to commute by private vehicle than consonant urbanites but not quite as likely as true suburbanites" [42].

The consortium of the European project TRANSPLUS [12] was concerned with best practices about the integration of transport and land use plans and policies towards sustainability. It created a framework for the analysis of land-use and transport case studies in Europe and experiences of reallife planning initiatives.

The PLUME project created a thematic network for the optimization of scientific networking, management, coordination, monitoring, exchange of information and exploitation and dissemination activities with main mission the integration of land-use and mobility planning, involving a variety of stakeholders from the research community to local experts in the cities of Europe [8].

\subsection{The wider environment (external factors)}

Goldman and Gorham [23] examined the concept and implementation of sustainable urban transport. According to this research, to be successful, "sustainable transport policy must avoid the common transportation policy pitfall of ignoring the larger systems in which transportation activity is embedded". Innovation is a key contributor in achieving sustainable transportation. The authors recognized four emerging areas of innovation: New Mobility, City Logistics, Intelligent System Management, and Livability.

Taylor et al. [46] conducted an interesting cross-sectional analysis of transit use in 265 urbanized areas in the US and constructed two-stage simultaneous equation regression models to account for simultaneity between transit service supply and consumption. The most important finding of their analysis is that four general factors outside the control of public transport systems explain most of the variation in transit ridership in urbanized areas: regional geography, metropolitan economy, population characteristics and auto/ 
highway system characteristics. Another interesting result of their survey is that fare levels and service frequency could account for at least a doubling (or halving) of transit use in a given urbanized area. According to the authors, "the observed influence of these two factors is consistent with both the literature and intuition: frequent service attracts passengers, and high fares drive them away" [46].

Nicolas et al. [36] applied the theme of sustainable development to the case of urban transport and daily mobility of the inhabitants of a city to verify the feasibility and the usefulness of elaborating such sustainable mobility indicators. The authors propose a set of indicators, which simultaneously takes into account the three dimensions of sustainability - environmental, economic and social.

\subsection{Market segmentation and user oriented approaches}

Cherchi and Cirillo [7] used panel data to estimate a mode choice model that accounts for systematic heterogeneity over individual preferences and responses, and correlation across individuals over three time periods and across individuals and members of the families over six weeks. Their results suggest that "individual tastes for time and cost, and in particular the subjective value of time (SVT) point estimates, are fairly stable but there is a significant systematic and random heterogeneity around these mean values and in the preferences for the different alternatives" [7].

In their work aiming to develop an attitudinal market segmentation approach to mode choice and ridership forecasting, Outwater et al. [37] concluded that "individuals more aware of environmental issues are more motivated to use public transport, while on the contrary travelers more sensitive to stress tend to prefer car over public transport for non-work trips".

Siddall et al. [43] conducted a user-centered design research to better understand how people use transit products and services throughout Northeastern Illinois, and to facilitate future improvements. Their targeted research produced detailed information about the characteristics and goals of users of various information products, how they are using the different sources, and what modifications might best serve specific customer needs. Furthermore, their "foundational research findings are more general and comprehensive in nature, and will inform and guide future efforts to establish regional information design standards for transit" [43]. In a similar context, Minser and Webb [35] explored the influencing factors of public transportation customer loyalty using structural equation modeling. One of their most important findings is that passengers' preconceived knowledge about a transit agency greatly influences their assessment on service delivery and value. For example, poor agency communication with stakeholders may negatively affect service ratings.
In their survey conducted in the San Francisco Bay Area in 1998, Collantes and Mokhtarian [9] explored the determinants of individuals' subjective assessments of their mobility. Their study provides insight into the way individuals mentally process the amount of travel they do, which will increase the understanding of travel behavior and its motivations. A variety of personal factors were found to significantly influence such assessments: personality traits, travelrelated attitudes, lifestyle characteristics, and affinity for travel.

\subsection{Transport demand and travel behavior}

The driving factors of passenger transport were examined by de Jong and van de Riet [14]. Their research aimed at (re)structuring the many different insights in a single conceptual model, reviewing the key drivers, and how each affects the various choices that travelers make (activity type, destination, mode, time-of-day and route) and the resulting impact on overall passenger transport demand. According to their conclusions, the most important determinant of passenger transport demand in total, and of kilometres by car in particular, is household disposable income. The authors highlight that the availability of private modes (car ownership) is crucial as well, but their future development depends to a large extent on income growth.

Peirce and Lappin [38] assessed the levels of awareness and use of low- and high-tech sources of traveler information in a panel survey of Seattle-area residents. The authors found that despite large increases in respondents' access to mobile phones and the Internet frequent use of traveler information is still largely concentrated among employed commuters, who tend to use conventional radio traffic reports.

Fujii and Taniguchi [20] reviewed the literature on travel feedback programs (TFPs), involving soft measures designed to change travel behavior, mainly from automobile to non-automobile travel, in mobility management. They classified TFPs using four main factors: place, technique, procedure, and communication media, and reviewed the effectiveness of 10 TFPs in Japan. They found that "TFPs reduced CO2 emissions by about $19 \%$ and car use by about $18 \%$, while increasing the use of public transport by about $50 \% "[20]$.

\subsection{Transit integration to other modes}

Bos et al. [4] conducted an analysis using a ContextDependent Hierarchical Choice Experiment to examine the choice of Park and Ride (P\&R) facilities. Their results indicate that "safety, quality of public transport and relative travel times by transport modes are key attributes to the success of P\&R facilities. Contextual variables seem to have 
only a minor impact" [4]. Bos et al. [5] used a P\&R choice model to assess the impacts of policy measures on $P \& R$ choice. According to their research, "the implementation of combined policy measures to improve the quality of both the $\mathrm{P} \& \mathrm{R}$ facility and the connecting public transport and to discourage car drivers to use their car for door-to-door trips have large, positively effects on the use of the P\&R alternative" [5].

The integration of cycling to public transport has received major attention in recent years by researchers worldwide. Bachand-Marleau et al. [2] conducted a survey in Montreal exploring the potential integration of the local public bikesharing system with transit. According to their results, bringing the bicycle onboard the transit vehicles is the preferred form of integration followed by bike\&ride schemes. In the same context, Krizek and Stonebraker [30] described and evaluated four common bicycle and transit integration strategies and assessed their cost-effectiveness. Their results confirm the findings of the previous researchers, since cyclists prefer the bicycle onboard transit strategy. However, enhancing bicycle parking at a transit stop proved more cost effective when compared against bicycle onboard transit configuration.

\subsection{Know-how and best practices transfer}

The establishment of mobility centers in urban areas aiming to facilitate commuters' and travelers' mobility is one of the measures that has gained recognition in recent years. In this context, the recently completed project MOBI-NET aimed at creating a European Network of know-how on sustainable mobility promoting the concept of mobility centers. The purpose of the know-how transfer among mobility centers is to learn from each other and to optimize the implementation of local actions. The project produced a guidebook for setting up a mobility centre [18].

The SMILE project aimed to help local authorities cope with the challenge of reconciling citizens' mobility needs with quality of life and environment by presenting good practices and introducing innovative approaches on a permanent basis [11]. The project compiled the results and experiences of European cities and towns in designing projects and measures according to the needs of specific target groups and presented successful models on how to involve citizens.

2.7 Innovation and guidance for the implementation of measures

The mission of the NICHES project was to stimulate a wide debate on innovative urban transport and mobility between relevant stakeholders from different sectors and disciplines across Europe [10]. NICHES promoted the most promising new concepts, initiatives and projects, to move them from their current 'niche' position to a 'mainstream' urban transport policy application. Some of the innovative concepts promoted by this project refer to Call-a-bus Services, Biogas in Captive Fleets, Public Bicycles and Urban Liftsharing Services.

In order to assess mobility management measures, a Monitoring and Evaluation Toolkit (MET) was developed within the MOST research project. MOST-MET offers a step-by-step guide to what one should do in the monitoring and evaluation process of the mobility management measures that one plans to implement [19]. It includes both a way to describe the measures (and the rationale for their selection) and the means to build-in a Monitoring and Evaluation process to assess impacts once the measures are implemented.

\subsection{Other initiatives}

In addition to the above projects, EPOMM (the European Platform on Mobility Management, http://www.epomm.eu/) provides a forum for all those interested in mobility management: representatives from EU member governments and other European countries, local and regional authorities, knowledge institutes, universities, researchers, transport operators and other user and interest groups. EPOMM developed itself as a strong, co-operative and balanced network of all actors involved in mobility management in Europe, which provides a well-known network and reference point for all interested actors [17].

Additional knowledge in the field has been developed in other countries around the world, such as the innovative mobility management project conducted by MIT [33], which has issued reports about best practices implemented worldwide and has recently started the Future Urban Mobility initiative within the SMART research initiative in Singapore (http://smart.mit.edu). A second initiative carried out in the U.S. is the Innovative Mobility Research (IMR) group [28]. IMR is based at the Transportation Sustainability Research Center (TSRC) at the University of California, Berkeley, and the current research areas include: goods movement, intelligent transportation systems (ITS), transit connections, mobility for special population groups, and alternative land use and transport futures. IMR designs research projects and conducts evaluations throughout the State of California, the U.S.A., and internationally.

\subsection{Synthesis}

The summary of the literature and state-of-the-art review provided above testifies that extensive and outstanding academic and R\&D efforts have been made worldwide. They have derived models, systems, methodologies, techniques, guidelines and awareness campaigns addressing different aspects of mobility management. Their ultimate objectives are to contribute to innovation and to create a sustainable 
urban mobility, as well as to make public transport systems and services more suitable to the transport demand profiles of the cities.

According to the review, particular attention has been paid to the relationship between the spatial environment and urban mobility, and mainly the choice of the transport mode. The external factors that affect and explain the variation in transit ridership have been addressed, as well as the driving factors of passenger transport. The needs and preferences of particular market segments and user groups have been thoroughly examined. More focused research has also been conducted on traveler information systems, Part \& Ride schemes and others.

The present paper adds another dimension to the existing literature. Using statistical methods, the paper contributes to a better understanding of the factors effecting commuters' choice in the use of transport modes and the main reasons that discourage them in using public transport. The research demonstrates how probit and structural equation models, as well as additional statistical analysis can be used to gain better insight of the commuters' mobility behavior and to apply adaptive and more effective mobility management policies. The gender- and age-based market segmentation analysis will shed further light on the mobility behavior of specific target groups.

\section{Methodology}

\subsection{Case study setup}

The data used in this research were collected in the context of the project "Development and operation of a pilot mobility center in the Municipality of Kalamaria in the framework of the project MOBI-NET". The project aimed at establishing a mobility center in the Municipality of Kalamaria (Thessaloniki, Greece, a map of which is shown in Fig. 1) providing those services to the citizens that will assist their mobility in the greater urban area.

The main services of the mobility center established in the Municipality of Kalamaria are: point-to-point mobility guidance and support; mobility guidance to predefined points of interest and the region's gateways (port, airport, etc.); information provision about urban transport and points of interest; support for mobility impaired people; and ticketing services for urban and interurban transport. The mobility center is in operation since July 2008 .

\subsection{Survey organization and questionnaire design}

A questionnaire survey was conducted prior to the mobility centre development in March 2008 aiming to acquire the
Fig. 1 The study area Municipality of Kalamaria

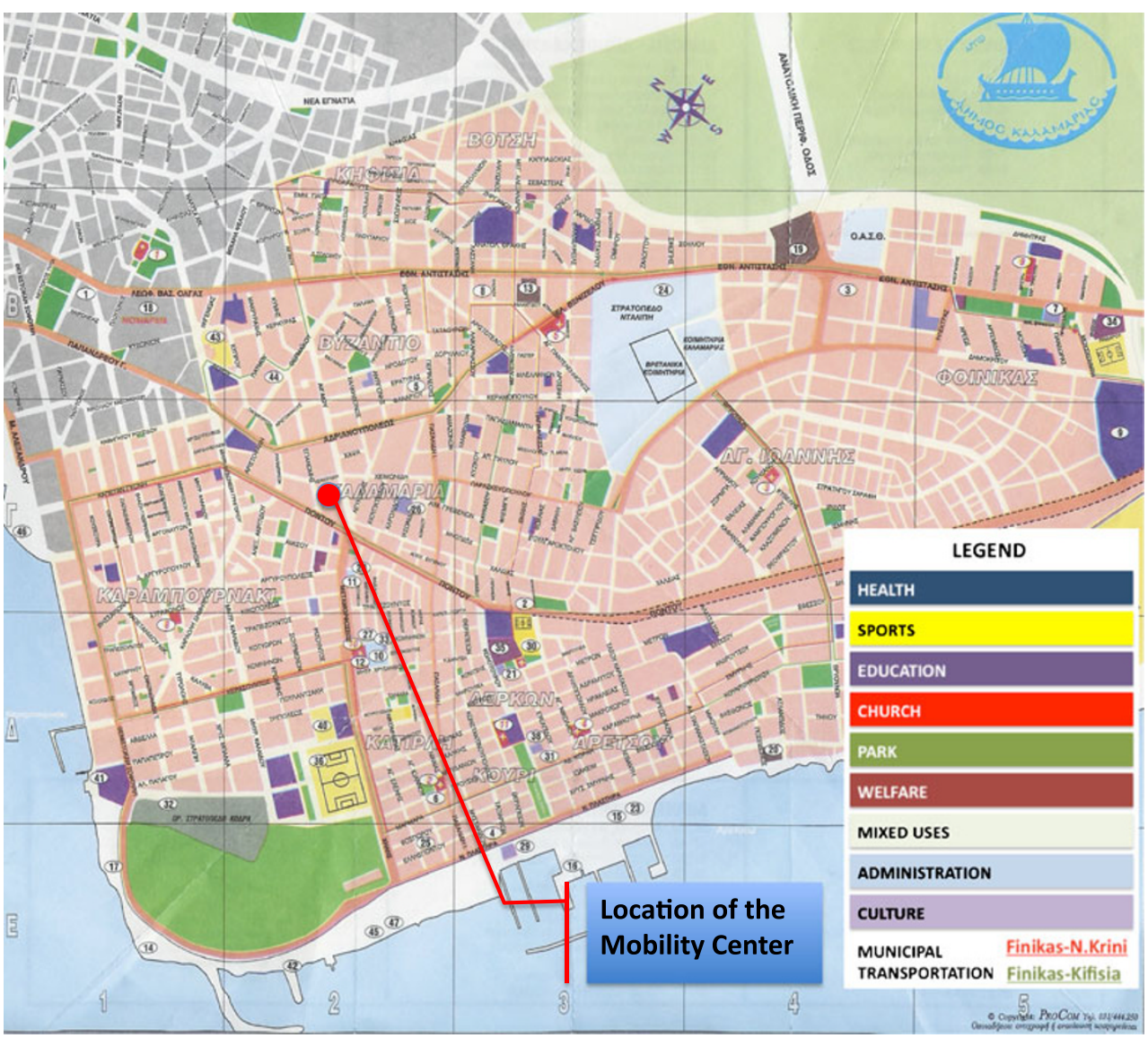


mobility characteristics in the Municipality of Kalamaria, the needs and requirements of the citizens, the factors that affect the choice of the mode to be used in their trips, their preferences on the services of a mobility center, and other mobility oriented attributes. 600 adult citizens responded to the survey (driving is only allowed to people above 18 years of age in Greece, and excluding younger participants was essential in making the mode choice realistic).

The survey was organized in two parts. First, a series of questions pertaining to the travel choices of the respondents and the mobility center were asked. Then, demographic and socioeconomic questions were asked, including age, gender, marital status, number of kids, education level and occupation. An advantage of this ordering of the two parts of the survey, i.e., asking socioeconomic questions after the main part of the survey, is that the respondents are not made explicitly aware of their socioeconomic status when answering the questions, and as such response bias and anchoring may be reduced. The questions included in the first part of the questionnaire address the following topics:

- Transport mode(s) the respondents use in their daily trips

- Frequency of the use of each transport mode

- Indication of the three most important destinations

- The degree that a list of factors affect the choice of mode the respondents use for their daily trips (top part of Table 1)

- The degree that a list of factors discourage the respondents from using public transport (bottom part of Table 1)
- Level of effectiveness of several means of awareness (tables of journeys located in the stops, Internet, VMS, etc.) in support of the respondents' mobility

- Usefulness of a series of services of a mobility center

- Frequency in the potential use of a mobility center

Two of the above questions (marked with (-)) were of particular interest for the research conducted in the framework of this article. Table 1 outlines these two questions.

While a detailed presentation of the sample is not within the scope of this paper, some key statistics are provided next. 9.4\% of the sample was between 18 and 24 years of age, $14.1 \%$ were between 25 and 34 years old, $23.3 \%$ were between 35 and 44 years old, $21.1 \%$ were between 45 and 54 years old, $19.6 \%$ were between 55 and 64 years old and $12.5 \%$ were older than 64 years. $34 \%$ of the respondents were male, while $66 \%$ of the sample was female. This disparity is due to the way the survey was completed (random phone interviews) and reflects the increased probability of finding a female person at home during the day. Several steps were taken in the model development and data analysis to mitigate the potential impact of the unbalanced (in terms of gender) sample in the model results and subsequent analysis. First, the gender was introduced as an explanatory variable in the model development and additional models have been developed, in which the observations have been weighted by female participation in the sample. Furthermore, market segmentation with respect to the gender was performed, developing separate models for male and female respondents. Finally, $62 \%$ of the retained observations indicated car as their habitual mode, with the remaining $38 \%$ using bus. Seven respondents who indicated taxi as their habitual mode and seven respondents who indicated two-wheeler were

Table 1 Part of the questionnaire, including the key questions

\begin{tabular}{|c|c|c|c|c|c|c|}
\hline & Not at all & A little & Somewhat & A lot & Very much & No answer \\
\hline \multicolumn{7}{|c|}{ To what degree do the following factors affect the choice of mode that you use for your daily trips? } \\
\hline Availability of parking space & 1 & 2 & 3 & 4 & 5 & 9 \\
\hline Availability of good transport links & 1 & 2 & 3 & 4 & 5 & 9 \\
\hline Traffic congestion & 1 & 2 & 3 & 4 & 5 & 9 \\
\hline Travel distance and time & 1 & 2 & 3 & 4 & 5 & 9 \\
\hline Cost of travel (gas or fare) & 1 & 2 & 3 & 4 & 5 & 9 \\
\hline Other & 1 & 2 & 3 & 4 & 5 & 9 \\
\hline \multicolumn{7}{|c|}{ To what degree do the following factors discourage you from using public transport (PT)? } \\
\hline Lack of information for PT schedules and lines & 1 & 2 & 3 & 4 & 5 & 9 \\
\hline Lack of good transport links and services & 1 & 2 & 3 & 4 & 5 & 9 \\
\hline Bad accessibility to public transport means & 1 & 2 & 3 & 4 & 5 & 9 \\
\hline High public transport fare & 1 & 2 & 3 & 4 & 5 & 9 \\
\hline Long transport time & 1 & 2 & 3 & 4 & 5 & 9 \\
\hline Substandard in-vehicle services conditions (crowding) & 1 & 2 & 3 & 4 & 5 & 9 \\
\hline Unreliability of transport services (e.g. in services frequency) & 1 & 2 & 3 & 4 & 5 & 9 \\
\hline
\end{tabular}


removed from the sample to avoid model specification and estimation (i.e., numerical) issues.

\subsection{Analysis plan}

The analysis presented in the next section is based on the two main questions of the questionnaire, presented in Table 1. The objective of this analysis is two-fold, i.e. to gain insight into the factors that:

- Affect the habitual mode choice, used by the respondents for their daily trips; and

- Discourage the use of public transport.

The analysis was performed using the R Software for Statistical Computing (R [40]) version 2.15.1 with the "lavaan" package [41] for the structural equation model and the "gplots" package [51] for Fig. 3.

\section{Analysis}

This section presents the main statistical modeling performed within this research, in particular the probit choice models, the structural equation model and the summary analysis of the factors discouraging the use of public transport.

\subsection{Probit choice models}

For the first step of the analysis, binary probit models were specified and estimated. The dependent variable in these models was the habitual mode choice (passenger car vs. public transport, which in the case of Thessaloniki currently amounts to bus). Table 2 presents the estimation results for the model for all respondents, as well as the results of another model in which the observations has been weighted to account for the imbalance between male and female respondents in the sample. A large number of explanatory variables was considered, including the questions on the degree that each factor affects the habitual mode choice (top of Table 1), demographic and socioeconomic data. The retained variables in the final model were based both on goodness-of-fit statistics (such as their significance, as indicated by the $t$-test, and their contribution to the model fit, as indicated by the Akaike Information Criterion, AIC, [1]), as well as on the sign and relative magnitude of the estimated coefficients. Note that in interpreting the estimated coefficients, the explanatory variable is coded as a binary $(0 /$ 1) factor with car being zero and bus being one. Therefore, the resulting probabilities can be interpreted as probabilities to choose bus. The first four parameters ("Degree ..."), which take integer values between 1 and 5 , cannot be directly incorporated into the model [50]. Therefore, binary (0/1) dummy variables have been created and evaluated. For example, the retained variable "Parking availability affects significantly" takes the value 1 if the respondents indicated that parking availability affects "A lot" and "Very much" (i.e. the two higher levels) and 0 otherwise. Other variables, such as Gender (Female), Internet familiarity, and the age groups were also coded as binary $(0 / 1)$ factors, with 1 meaning that the respondent falls into this category and 0 otherwise. Trip purposes by mode were also coded as dummy variables. Note that the trip purpose was collected using two different questions: one for the trip purpose if the mode chosen is car and one if the mode chosen is bus. Not all trip purposes were retained.

A negative intercept in the model suggests that - as expected - ceteris paribus a preference for car exists. Based on the presented model estimation results, a key factor

Table 2 Model estimation results (all respondents)

\begin{tabular}{|c|c|c|c|c|}
\hline & \multicolumn{2}{|c|}{ ALL RESPONDENTS } & \multicolumn{2}{|c|}{ ALL RESPONDENTS Weighted by gender } \\
\hline & Estimate & $t$-test & Estimate & $t$-test \\
\hline (Intercept) & -1.706 & -5.780 & -1.725 & -7.240 \\
\hline Parking availability affects significantly & -0.623 & -3.038 & -0.562 & -3.085 \\
\hline Female & 0.579 & 2.450 & 0.574 & 3.135 \\
\hline No Kids & 0.531 & 2.053 & 0.461 & 1.962 \\
\hline Trip purpose: leisure (for car trips) & 1.095 & 4.012 & 1.193 & 4.897 \\
\hline Trip purpose: personal affair (for car trips) & 0.503 & 1.896 & 0.489 & 2.010 \\
\hline Trip purpose: other/no answer (for car trips) & 3.672 & 11.472 & 3.592 & 13.399 \\
\hline Trip purpose: other/no answer (for bus trips) & -1.111 & -2.664 & -1.154 & -2.889 \\
\hline Observations & 511 & & 511 & \\
\hline Null deviance (d.o.f) & 663.10 & (510 d.o.f.) & 863.06 & (510 d.o.f.) \\
\hline Residual deviance (d.o.f) & 196.01 & (503 d.o.f.) & 246.79 & (503 d.o.f.) \\
\hline AIC & 212.01 & & 262.79 & \\
\hline
\end{tabular}


affecting the preference of respondents toward passenger car is the existence of parking space. This is an expected finding, confirming that parking is a major concern for commuters. Furthermore, the fact that no other parameter (from the group of service oriented factors that were considered) enters the model indicates that - among these factors - parking availability in essence dominates the mode choice of drivers. This might appear to be a simplistic approach to handling the situation, but on the other hand it may mean that the efforts of policy makers and administrators could more effectively be focused on this single factor. It is worth noting, at this point, that illegal parking is not well-enforced in Greece [44].

The gender-based dummy variable (female) indicates that female respondents and respondents without kids have a lower preference (than other respondents) for car. This seems like a reasonable finding and is consistent with the literature [42]. Turner and Niemeier [49] suggest that public transport and "slow" modes of transport may be more acceptable to women than to men, because their commutes tend to be shorter than men's. The estimation results may also reflect women's lower bargaining power in household negotiations of auto use [31,39]. The existence of kids adds further constraints and therefore it is reasonable to find that respondents without kids are more likely to choose bus for their trips. However, it should be stressed that considering the relative magnitude of the estimated coefficients (intercept - "female" coefficient "no kids" coefficient), even female respondents without kids have a preference for car over bus, albeit lower than other respondents. Additional constraints, such as car ownership information could perhaps provide further insight into this parameter (if e.g. a higher use of public transport by women could be observed for families with a single car).

Trip purpose is commonly used in modeling habitual mode choice, especially for car trips. Note that the question was worded in this survey as "please indicate the most common trip purpose for your car trips" (and respectively the public transport trips). As mentioned above, in this model, trip purpose for a given model is entered as $0 / 1$ binary dummy variables. It is therefore implied that the value for the options that are not included is not significantly different from zero. The fact that the other trip purposes are associated with a positive coefficient (for car) indicates that people are less likely to use car for these trip purposes. Similarly, the negative coefficient for "other trips" by bus indicates that there is a smaller preference towards bus for this category of trips.

Finally, it is noted that while there are some changes in the estimated coefficient values between the two models presented in Table 2 (base one and one where the observations have been weighted to account for the underrepresentation of male respondents in the sample), the underlying trends still apply.

A gender-based market segmentation analysis follows (Table 3). The results for the model estimated using only female respondents are similar and consistent with those for
Table 3 Model estimation results (gender-based market segmentation)

\begin{tabular}{lll}
\hline & \multicolumn{2}{l}{ Female } \\
\cline { 2 - 3 } & Estimate & $t$-test \\
\hline (Intercept) & -1.082 & -4.085 \\
Parking availability affects significantly & -0.771 & -3.144 \\
No Kids & 0.668 & 2.278 \\
Trip purpose: shopping (for car trips) & 0.929 & 2.912 \\
Trip purpose: leisure (for car trips) & 0.536 & 1.792 \\
Trip purpose: personal affair (for car trips) & 3.971 & 8.585 \\
Trip purpose: other/no answer (for car trips) & -1.074 & -2.388 \\
& & \\
Observations & 335 & \\
Null deviance (d.o.f) & 454.66 & $(334$ d.o.f.) \\
Residual deviance (d.o.f) & 142.84 & $(328$ d.o.f.) \\
AIC & 156.84 & \\
\hline
\end{tabular}

the entire sample. However, some observations can be made from the relative magnitude of the obtained coefficients. Based on the magnitude of the intercept, it can be argued that female respondents show a lower tendency towards the car, which might be a reflection of lower female labor participation and the fact that women in general tend to do shorter trips (that can be more easily accommodated by public transport). The value of the intercept in this model is roughly the same as the difference of the intercept and the "female" coefficient in the model for all respondents (Table 2).

One of the main limitations of the presented probit models is that travel cost and travel time do not appear in the model specification due to the orientation of the initial survey. This may lead to confounding and its associated effects [24]. However, this data is not available in this survey; in practice, it is not uncommon, when repurposing data from a survey, to have to deal with data limitations. To overcome this, further analysis using structural equation models is presented in the next subsection.

\subsection{A structural equation model}

Besides the probit models, a structural equation model has also been estimated, the structure of which is shown in graphical form in Fig. 2. The latent variable reflects the underlying mobility behavior of the respondents and is based on five indicators, i.e. the degree that parking, good transport link, congestion, travel distance and time and travel cost affect their mode choice. Besides the latent variable, gender and age play a role. The estimation results are presented in Table 4 . The top part of Table 4 shows the estimation results for the regression equation.

As before, female respondents show a higher tendency towards bus. Furthermore, respondents in the age group 36- 
Fig. 2 Path diagram of the structural equation model
Degree ... affects mode choice

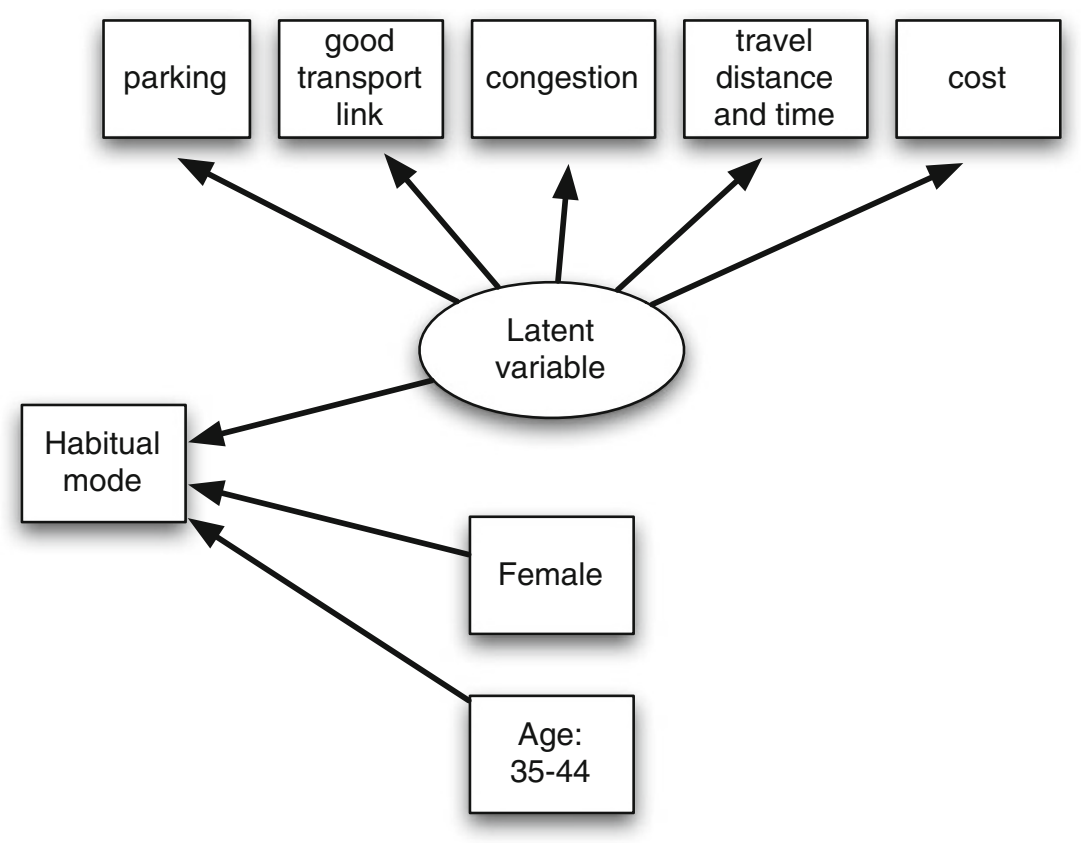

44 years old, show a higher tendency towards car. This is an intuitive finding, as these respondents are in the prime of their professional life and therefore can benefit from the increased mobility offered by the private automobile.

Three summary measures of goodness of fit are reported: Standardized Root Mean Square Residual (SRMR), Root Mean Square Error of Approximation (RMSEA) and the Comparative Fit Index (CFI). Hooper et al. [25] provide a detailed overview of the measures of goodness of fit for structural equation models and how they can be interpreted. Values of the SRMR range between zero and one, with wellfitting models having values less than 0.06 [6,15], while values up to 0.08 can be considered acceptable [27]. The obtained value of 0.06 for this model can therefore be reasonably accepted. The appropriate acceptable cut-off point for the RMSEA has been a topic of debate, but in general lies within 0.06 [27] and 0.08 [32], while 0.07 is often considered as having the general consensus [45]. As such, the obtained value for this model (0.081) is marginally acceptable. The third goodness of fit measure, the Comparative Fit Index (CFI) is the one that provides worse performance (with a value of 0.811 ), as values larger of 0.90 or even 0.95 are advised [27].

\subsection{Factors discouraging use of public transport}

Having obtained some insight into the impact of various parameters in the habitual mode choice of commuters in an area of Thessaloniki, it is interesting to obtain further insight into the degree that various factors discourage the use of public transport. Figure 3 summarizes the findings of this survey with respect to the extent that various factors discourage the use of public transport, both for all respondents, as well as for market segmentation by gender.

Looking first at the entire sample, it seems that the factor that discourages most respondents is crowding, followed by service unreliability. The least concern is the high fare, which reflects the relatively low public transport fare in Greece ( 80 cents normal fare for a single trip for the bus services in Thessaloniki). In the same direction, the lack of public transport information and the bad accessibility to the transit network do not seem to affect respondents' preference to public transport either. The first finding reflects the general behavior of the Greek passengers, who traditionally pay little attention on transit information tables, while the second may be justified by the sufficient coverage of the study area with public transportation.

Looking at the market segmentation figures, several observations can be made. For example, it seems that female respondents indicated a higher sensitivity (i.e. tendency to be discouraged) overall, as opposed to the male respondents.

These findings can be useful in developing strategies for the promotion of urban mobility through public transport. For example, given the high acceptability that the respondents show to the current fare levels, one could argue that modest fare increases might not discourage the use of the public transport services. If the additional revenue could be redirected to improve other aspects that according to the respondents discourage their use of public transport, then there could be a significant net overall benefit. The idea would be to investigate whether it would be possible and practical to find a trade-off between decreasing the 
Table 4 Structural equation model estimation results

\begin{tabular}{|c|c|c|c|}
\hline & Estimate & $\begin{array}{l}\text { Standard } \\
\text { error }\end{array}$ & z-value \\
\hline \multicolumn{4}{|l|}{ Regressions: } \\
\hline HabitualMode & $\sim$ & & \\
\hline Latent variable & -0.123 & 0.051 & -2.408 \\
\hline Female & 0.198 & 0.043 & 4.620 \\
\hline $\begin{array}{l}\text { Age group } 36-44 \text { y.o. } \\
\text { Latent variables: }\end{array}$ & -0.196 & 0.048 & -4.129 \\
\hline Latent variable & $=\sim$ & & \\
\hline Degree Parking Affects & 1 & & \\
\hline $\begin{array}{l}\text { Degree Good Transport } \\
\text { Link Affects }\end{array}$ & 1.084 & 0.215 & 5.051 \\
\hline Degree Congestion Affects & 1.569 & 0.276 & 5.679 \\
\hline $\begin{array}{l}\text { Degree Travel Distance and } \\
\text { Time Affects }\end{array}$ & 1.768 & 0.311 & 5.683 \\
\hline Degree Cost Affects & 0.936 & 0.196 & 4.775 \\
\hline \multicolumn{4}{|l|}{ Variances: } \\
\hline Degree Parking Affects & 2.119 & 0.142 & \\
\hline $\begin{array}{l}\text { Degree Good Transport } \\
\text { Link Affects }\end{array}$ & 1.543 & 0.108 & \\
\hline Degree Congestion Affects & 1.047 & 0.104 & \\
\hline $\begin{array}{l}\text { Degree Travel Distance and } \\
\text { Time Affects }\end{array}$ & 1.068 & 0.121 & \\
\hline Degree Cost Affects & 1.536 & 0.105 & \\
\hline Habitual Mode & 0.209 & 0.013 & \\
\hline Latent variable & 0.275 & 0.087 & \\
\hline Number of observations & 511 & & \\
\hline \multicolumn{4}{|c|}{ Log likelihood and information criteria } \\
\hline \multicolumn{2}{|c|}{ Log likelihood user model (H0) } & \multicolumn{2}{|l|}{-5304.78} \\
\hline \multicolumn{2}{|c|}{ Log likelihood unrestricted model (H1) } & \multicolumn{2}{|l|}{-5263.70} \\
\hline \multicolumn{2}{|l|}{ Number of free parameters } & \multicolumn{2}{|l|}{14} \\
\hline \multicolumn{2}{|l|}{ Akaike (AIC) } & \multicolumn{2}{|l|}{10637.56} \\
\hline \multicolumn{2}{|l|}{ Bayesian (BIC) } & \multicolumn{2}{|l|}{10696.87} \\
\hline \multicolumn{2}{|c|}{ Sample-size adjusted Bayesian (BIC) } & \multicolumn{2}{|l|}{10652.43} \\
\hline \multicolumn{2}{|l|}{ SRMR } & \multicolumn{2}{|l|}{0.06} \\
\hline \multicolumn{2}{|l|}{ RMSEA } & \multicolumn{2}{|l|}{0.081} \\
\hline \multicolumn{2}{|l|}{ Comparative Fit Index (CFI) } & \multicolumn{2}{|l|}{0.811} \\
\hline
\end{tabular}

performance in a factor that the potential passengers are not very sensitive to and using the residual resources to improve the performance related to a factor that the population is very sensitive to. It needs to be stressed that while the findings of this research and the methodology used may be of general interest; the results might not be the same elsewhere.

\section{Conclusions}

The formulation of a sustainable urban mobility environment goes far beyond the provision of effective public transport solutions; it includes adaptive transit services, modern infrastructure, traffic management tools, awareness campaigns, well coordinated mobility schemes and advanced ITS solutions, that all together enable citizens to satisfy their mobility needs. It also requires a deep understanding of the local mobility conditions and patterns, as well as the key factors that dominate the preferences and modal choices of citizens in urban mobility. Understanding human behavior can then be used to develop strategies and incentives that may help steer the respondents towards a higher use of public transport.

The primary reasons for not using public transport and the possible solutions to change habitual behavior have been subject to thorough research the recent years. According to Fujii et al. [21], one reason could be the usual negative image associated with public transport, especially the one associated with bus, while Beirão and Cabral [3] found that private car users usually display an erroneous perception of public transport system performance. Furthermore, Horeni et al. [26] claim that habitual car users usually lack knowledge about alternatives modes, so it is important to provide them information about the advantageous of public transport and walking. In their research, Gardner and Abraham [22] concluded that "providing greater access to service information and more interactive services (e.g. real-time timetable information) may be a way to increase individuals' perceptions of control with public transport".

The analysis presented in this paper aims to provide some insight into the key factors affecting the commuters' modal choices and the main reasons that discourage commuters from using public transport services. The estimated binary probit and structural equation models demonstrated factors affecting modal choice, while the further statistical analysis drew useful information about the mobility behavior of commuters of different market segments. The data used in this analysis were collected during the establishment of a mobility centre in the region of Kalamaria, Thessaloniki, Greece.

The presented model estimation results confirm the expectation that overall people show a general preference for car over public transport. According to the analysis of the collected data, the main factor affecting the preference of respondents toward passenger car is the availability of parking space. Female respondents have a lower preference towards car than male respondents, while compared to the other age groups, respondents between the ages of 35 and 44 show a higher preference for car. Furthermore, while they still show an overall preference for car, respondents without kids are more likely than those with kids to choose transit for their trips. Concerning trip purpose, the general population and female respondents indicated a higher tendency for using car for work trips, followed by shopping and personal trips and finally leisure trips. 
Fig. 3 Impact of factors in discouraging use of public transport
How much does each of the following factors discourage your use of public transport?

(Figures represent percentage of respondents)

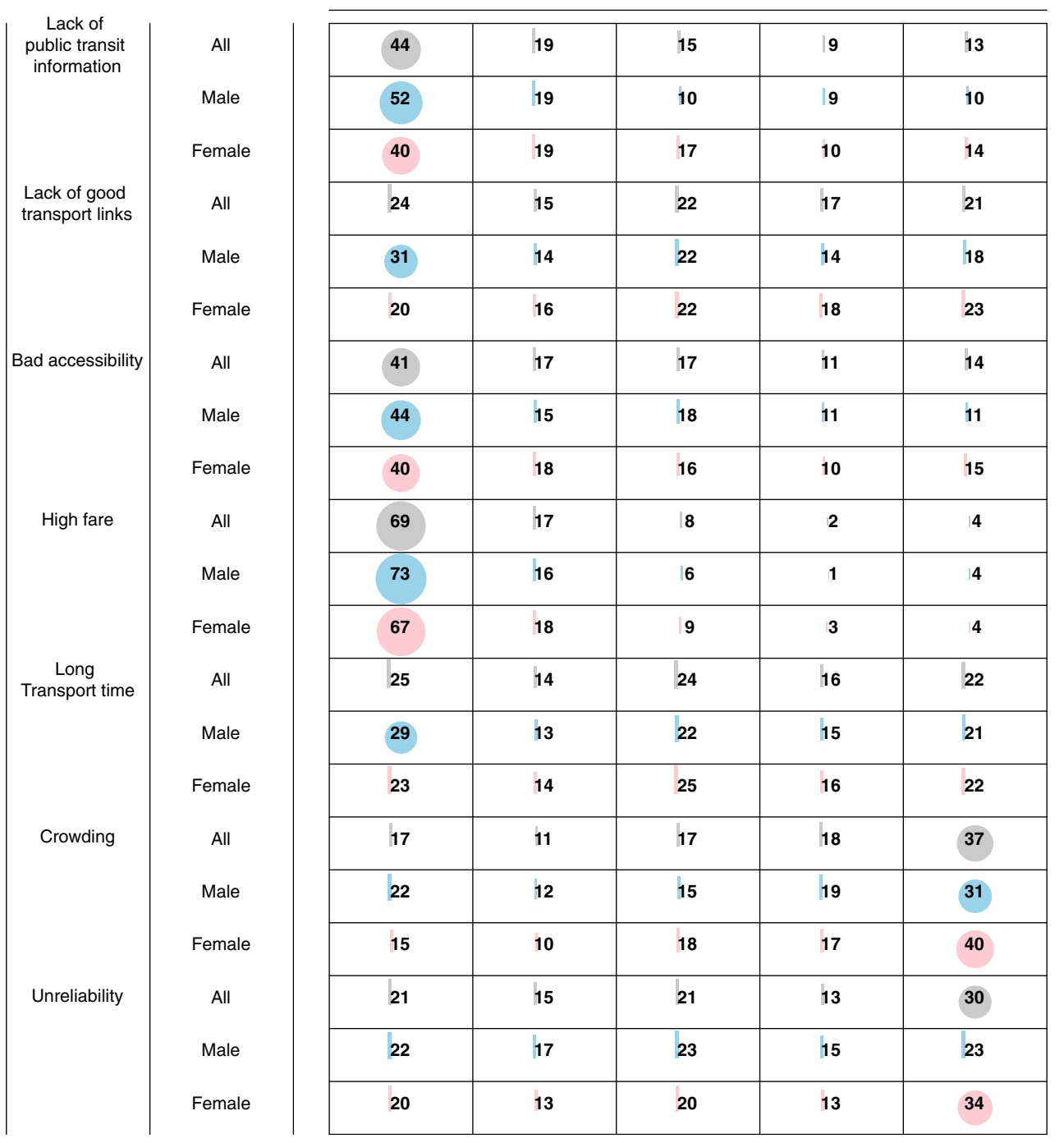

A point of particular interest in trying to influence mode choice is the understanding of the degree to which each factor discourages the use of public transport. It seems that the factor that discourages most respondents is crowding followed by service unreliability. The high fare, the lack of public transport information and the bad accessibility to the transit network do not seem to discourage respondents' use of public transport in the particular situation that was analyzed in this research.

Statistics is always a powerful tool that can be used by policy and decision makers to gain a better insight of the commuters' and travelers' mobility behavior, and to apply adaptive and more effective mobility management policies. The binary probit and structural equation models and the additional statistical analysis conducted in this research revealed some important findings for further research and exploitation. For example, the fact that high fare levels do not discourage commuters from using public transport, may allow policy makers to slightly increase fares and redirect additional revenue to improve other public transport services, which are more essential according to the commuters, such as crowding and service unreliability. Furthermore, the fact that parking availability dominates the mode choice of drivers can be used to widely implement police campaigns in order to enforce illegal parking and steer car drivers to use public transport, thus increasing transit ridership and opening the road for service improvements. Therefore, such findings may be quite useful for tactical and strategic planning to better tackle commuters' perception and to define the appropriate urban mobility management actions and policies.

Finally, it is recognized that more advanced models, such as an integrated latent variable and choice model [50] could provide an improved representation of the 
modeled phenomenon. Tsirimpa et al. [48] present an application of such models in modeling the impact of risk aversion on drivers' route switching perception, Kitrinou et al. [29] use it to model residential relocation decisions in island areas, while Daly et al. [13] apply the approach to assess the impact of security on rail travel behavior.

Open Access This article is distributed under the terms of the Creative Commons Attribution License which permits any use, distribution and reproduction in any medium, provided the original author(s) and the source are credited.

\section{References}

1. Akaike H (1973) Information theory and an extension of the maximum likelihood principle. In Second International Symposium on Information Theory (B. Petrox and F. Caski, eds.), Akademia Kiado, Budapest, 267-281. (Reprinted in Breakthroughs in Statistics, eds Kotz, S. \& Johnson, N. L. (1992), volume I, pp. 599-624. Springer, New York)

2. Bachand-Marleau J, Larsen J, El-Geneidy AM (2011) The much appreciated marriage of cycling and transit: But how will it work? Proceedings of the 90th Annual Meeting of the Transportation Research Board, Washington DC

3. Beirão G, Cabral JAS (2007) Understanding attitudes towards public transport and private car: A qualitative study. Transport Policy 14:478-489

4. Bos I, van der Heijden R, Molin E, Timmermans H (2004) The choice of park \& ride facilities: An analysis using a contextdependent hierarchical choice experiment. Proceedings of the 83rd Annual Meeting of the Transportation Research Board, Washington, DC

5. Bos I, van der Heijden R, Molin E, Timmermans H (2005) The impact of policy measures on $\mathrm{P} \& \mathrm{R}$ choice: Simulations based on a P\&R choice model. Proceedings of the 84th Annual Meeting of the Transportation Research Board, Washington, DC

6. Byrne BM (1998) Structural equation modeling with LISREL, PRELIS and SIMPLIS: Basic concepts, applications and programming. Lawrence Erlbaum Associates, Mahwah, New Jersey

7. Cherchi E, Cirillo C (2008) A modal mixed logit choice model on panel data: Accounting for systematic and random variations on responses and preferences. Proceedings of the 87th Annual Meeting of the Transportation Research Board, Washington DC

8. Clifford S, Blackledge D, May T, Jopson A, Sessa C, Haon S (2005) Final Report. Deliverable 11 of the project PLUME (PLanning and Urban Mobility in Europe), European Commission, 5th Framework Programme.

9. Collantes GO, Mokhtarian PL (2007) Subjective assessments of personal mobility: What makes the difference between a little and a lot? Transport Policy 14:181-192

10. Consortium of the European project NICHES (2006) Innovative Urban Transport Concepts, Deliverable of the project NICHES, European Commission, 6th Framework Programme.

11. Consortium of the European project SMILE (2004) Towards Sustainable Urban Transport Policies: Recommendations for Local Authorities, Deliverable of the project SMILE (Sustainable Mobility Initiatives for Local Environment), European Commission, LIFE Programme

12. Consortium of the European project TRANSPLUS (2002) Assessment of Barriers and Solutions, Deliverable 4.1 of the project TRANSPLUS (Transport Planning Land-Use and Sustainability), European Commission.
13. Daly AJ, Hess S, Patruni B, Potoglou D, Rohr C (2012) Using ordered attitudinal indicators in a latent variable choice model: A study of the impact of security on rail travel behaviour. Transportation 39 (2):267-297

14. De Jong G, Van de Riet O (2008) The driving factors of passenger transport. European Journal of Transport and Infrastructure Research 8(3):227-250

15. Diamantopoulos A, Siguaw JA (2000) Introducing LISREL. Sage Publications, London

16. European Commission (2007) Green Paper: Towards a new culture for urban mobility. Publication of the European Commission, $\operatorname{COM}(2007) 551$ final, Brussels.

17. European Platform on Mobility Management website: http:// www.epomm.org/. Accessed: July 20, 2008.

18. Farias, T., Taborda, S. and Stussi, R. (2007) How to set up a successful Mobility Centre? Deliverable 3.a of the project MOBI-NET (Mobility Centres Network), European Commission, Intelligent Energy Programme.

19. Finke T (2003) Monitoring and evaluation toolkit: A guide for the assessment of mobility management approaches, report of the project MOST (Mobility Management Strategies for the next Decades), European Commission, Competitive and Sustainable Growth Programme

20. Fujii S, Taniguchi A (2006) Determinants of the effectiveness of travel feedback programs - a review of communicative mobility management measures for changing travel behaviour in Japan. Transport Policy 13:339-348

21. Fujii S, Gärling T, Kitamura R (2001) Changes in drivers' perceptions and use of public transport during a freeway closure: Effects of temporary structural change on cooperation in a real-life social dilemma. Environ Behav 6:796-808

22. Gardner B, Abraham C (2007) What drives car use? A grounded theory analysis of commuters' reasons for driving. Transport Res F: Traffic Psychol Behav 3:187-200

23. Goldman T, Gorham R (2006) Sustainable urban transport: Four innovative directions. Technology in Science 28:261-273

24. Hess S (2005). Advanced discrete choice models with applications to transport demand, $\mathrm{PhD}$ dissertation, Imperial College London, Center for Transport Studies

25. Hooper D, Coughlan J, Mullen MR (2008) Structural equation modelling: Guidelines for determining model fit. The Electronic Journal of Business Research Methods 6(1):53-60

26. Horeni O, Garling T, Loukopoulos P, Fujii S (2007) An experimental simulation of adaptations to increased car-use costs. Transport Res F: Traffic Psychol Behav 4:300-320

27. Hu LT, Bentler PM (1999) Cutoff criteria for fit indexes in covariance structure analysis: Conventional criteria versus new alternatives. Struct Equ Model 6(1):1-55

28. Innovative Mobility Research website: http://www.innovativemo bility.org/. Accessed: July 27, 2008.

29. Kitrinou, E. A. Polydoropoulou, and D. Bolduc (2010). Development if Integrated Choice and Latent Variable Models for the Residential Relocations Decision in Island Areas. Choice Modelling: The State of the art and the state of practice. Proceedings from the Inaugural International Choice Modeling Conference. Chapter 27, pp 593-618. Edited by Stephane Hess and Andrew Daly. 2010 Emerald Group Publishing Limited 2010. ISBN: 978-1-84950-772-1.

30. Krizek KJ, Stonebraker EW (2011) Assessing options to enhance bicycle and transit integration. Proceedings of the 90th Annual Meeting of the Transportation Research Board, Washington DC

31. Law R (1999) Beyond "women and transport": Towards new geographies of gender and daily mobility. Prog Hum Geogr 23:567-588

32. MacCallum RC, Browne MW, Sugawara HM (1996) Power Analysis and Determination of Sample Size for Covariance Structure Modeling. Psychological Methods 1(2):130-49 
33. Massachusetts Institute of Technology, Center for Technology, Policy and Industrial Development (2000) International Mobility Observatory. Cooperative Mobility Program, USA

34. Meurs H, Haaijers R (2001) Spatial structure and mobility. Transportation Research Part D 6:429-446

35. Minser J, Webb V (2010) Quantifying the benefits: Application of customer loyalty modeling in a public transportation context. Proceedings of the 89th Annual Meeting of the Transportation Research Board, Washington DC

36. Nicolas J-P, Pocheta P, Poimboeuf H (2003) Towards sustainable mobility indicators: Application to the Lyons conurbation. Transport Policy 10:197-208

37. Outwater M, Castleberry S, Shiftan Y, Ben-Akiva M, Shuang Zhou Y, Kuppam A (2003) Attitudinal market segmentation approach to mode choice and ridership forecasting: Structural equation modeling. Transp Res Rec 1854:32-42

38. Peirce S, Lappin J (2003) Evolving awareness, use, and opinions of Seattle region commuters concerning traveler information: Findings from the Puget Sound Transportation Panel Survey, 1997 and 2000. Proceedings of the 82nd Annual Meeting of the Transportation Research Board, Washington D.C

39. Pickup L (1984) Women's gender role and its influence on travel behaviour. Built Environment 10:61-68

40. Development Core Team R (2012) R: A language and environment for statistical computing. R Foundation for Statistical Computing, Vienna, Austria

41. Rosseel Y (2012) lavaan: An R package for structural equation modeling. J Stat Softw 48(2):1-36, Available online: http:// www.jstatsoft.org/v48/i02/ (accessed: 10 October, 2012)

42. Schwanen T, Mokhtarian P (2005) What affects commute mode choice: Neighborhood physical structure or preferences toward neighbourhoods? J Transp Geogr 13:83-99
43. Siddall A, Pitstick M, Allen JG (2006) Transit products, services, and environments in a complex system: User-centered design research in Chicago. Proceedings of the 85th Annual Meeting of the Transportation Research Board, Washington DC

44. Spiliopoulou C, Antoniou C (2012) Analysis of illegal parking behavior in Greece. Proceedings of the Transport Research Arena (TRA) 2012 Conference, Athens

45. Steiger JH (2007) Understanding the limitations of global fit assessment in structural equation modeling. Personal Individ Differ 42(5):893-98

46. Taylor DB, Miller D, Iseki H, Fink C (2008) Nature and/or nurture? Analyzing the determinants of transit ridership in urbanized areas. Transportation Research Part A 43:60-77

47. Train K (2009) Discrete choice models with simulation, Second Edition, Cambridge University Press

48. Tsirimpa A, Polydoropoulou A, Antoniou C (2010) Development of a latent variable model to capture the impact of risk aversion on travelers" switching behavior. Journal of Choice Modeling 3 (1):127-148

49. Turner T, Niemeier D (1997) Travel to work and household responsibility: new evidence. Transportation 24:397-419

50. Walker J (2001) Extended discrete choice models: Integrated framework, flexible error structures, and 3Variables. Doctoral Dissertation. Department of Civil and Environmental Engineering, Massachusetts Institute of Technology

51. Warnes GR (2012) gplots: Various R programming tools for plotting data. $\mathrm{R}$ package version 2.11.0. http://CRAN.R-project.org/ package $=$ gplots [Includes $\mathrm{R}$ source code and/or documentation contributed by: Ben Bolker, Lodewijk Bonebakker, Robert Gentleman, Wolfgang Huber Andy Liaw, Thomas Lumley, Martin Maechler, Arni Magnusson, Steffen Moeller, Marc Schwartz and Bill Venables] 